\begin{tabular}{|c|c|c|}
\hline 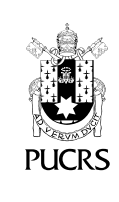 & $\begin{array}{l}\text { ESCOLA DE } \\
\text { HUMANIDADES }\end{array}$ & $\begin{array}{l}\text { Studies and debates in linguistics, literature and Portuguese language } \\
\text { Letras de hoje Porto Alegre, v. 56, n. 1, p. 41-52, jan.-abr. } 2021 \\
\text { e-ISSN: } \mathbf{1 9 8 4 - 7 7 2 6 ~ | ~ I S S N - L : ~ 0 1 0 1 - 3 3 3 5 ~}\end{array}$ \\
\hline http://d & $\mathrm{rg} / 10.15448 / 1984-7726.2021 .1 .37216$ & \\
\hline
\end{tabular}

SEÇÃO: TEMÁTICA LIVRE

\title{
Guimarães Rosa e Portugal
}

\author{
Guimarães Rosa and Portugal \\ Guimarães Rosa y Portugal
}

Gustavo de Castro ${ }^{1}$

orcid.org/0000-0001-7126-6947

gustavo.castro@fac.unb.br

\section{Paulo Alziro Schnor ${ }^{1}$}

orcid.org/0000-0003-2156-7180 pauloalziro@gmail.com

Recebido em: 28 fev. 2020 Aprovado em: $16 \mathrm{fev} .2021$ Publicado em: 11 jun. 2021.
Resumo: O presente trabalho trata-se de um relatório de pesquisa que investiga as relações de Guimarães Rosa com Portugal desde os aspectos de sua ancestralidade, passando por viagens e visitas a Lisboa, proximidades com intelectuais e editores como Jaime Cortesão, Aquilino Ribeiro, António Sousa Pinto, Arnaldo Saraiva e Óscar Lopes até o seu constante interesse pela cultura do país, em especial, a literatura, os estudos geográficos e culinários. Na conclusão, são apresentados os resultados, as lacunas e as perspectiva possiveis de novos estudos. Palavras-chave: Guimarães Rosa. Portugal. Literatura. História. Intelectuais.

Abstract: Research report that investigates Guimarães Rosa's relations with Portugal from the aspects of his ancestry, going through trips and visits to Lisbon, close by intellectuals and editors such as Jaime Cortesão, Aquilino Ribeiro, António Sousa Pinto, Arnaldo Saraiva and Óscar Lopes until the his constant interest in the country's culture, especially literature, geographic and culinary studies. In the conclusion, the results, gaps and possible perspectives of new studies are presented.

Keywords: Guimarães Rosa. Portugal. Literature. History. Intellectuals.

Resumen: Informe de investigación que investiga las relaciones de Guimarães Rosa con Portugal desde los aspectos de su ascendencia, pasando por viajes y visitas a Lisboa, cerca de intelectuales y editores como Jaime Cortesão, Aquilino Ribeiro, António Sousa Pinto, Arnaldo Saraiva y Óscar Lopes hasta su constante interés por la cultura del pais, especialmente la literatura, los estudios geográficos y culinarios. En la conclusión se presentan los resultados, brechas y posibles perspectivas de nuevos estudios.

Palabras clave: Guimarães Rosa. Portugal. Literatura. Historia. Intelectuales.

\section{Introdução}

Guimarães Rosa gostava de dizer que descendia dos Wimaranens (HOLLERER, 1962; SARAIVA, 1966; HARSS, 2012), povo que fundara um reino no norte de Portugal, antes da invasão dos Visogodos. ${ }^{2}$ Ao chegar no Brasil, os "Guimarães", segundo ele, geraram uma robusta descendência, espalhando-se por todas regiões do Brasil. Até mesmo os primeiros romancistas regionais de Minas, Bernardo Guimarães, na metade do século XIX, e o poeta místico Alphonsus de Guimaraens, tradutor de

\section{(c) (1)}

Artigo está licenciado sob forma de uma licença 
Heine, ${ }^{3}$ descendiam dessa progenitura. O ramo dos Guimarães do qual ele descendia prosperou com a administração de terras, compra e venda, vivendo em enormes extensões territoriais transformadas em fazendas de gado, no interior do Brasil. Por isso, "os Guimarães" da sua linhagem não eram nem sedentários, nem nômades, mas ambos. Esta característica ambivalente, de apego à terra e de desterro voluntário, marcaria a sua personalidade: "Guimarães Rosa personifica essa dualidade", escreveu Harss (2012, p. 152), referindo-se ao fato dele ser, simultaneamente, errante (por ser um diplomata) e ligado à tradição do culto à terra. Além dessa caracteristica ancestral, investigaremos neste artigo as relações profissionais, editorais, filosóficas e estéticas de Guimarães Rosa com Portugal. Ele chegou a listar as vezes que tinha estado naquele pais:

Estive em Portugal três vezes. Na primeira, em 1938, passei lá apenas um dia; ia a caminho da Alemanha. Na segunda, em 1941, passei lá quinze dias, em cumprimento de uma missão diplomática que me fora confiada em Hamburgo. Na terceira, em 1942, passei um mês, pois estava já de regresso ao Brasil, por causa da guerra (ROSA, [1966]).

Para analisar os dados dessas visitas, assim como as peças do conjunto das relações, viajamos a Lisboa, Porto e Guimarães no sentido de consultar arquivos, cruzar dados inicialmente levantados no Instituto de Estudos Brasileiros (IEB) da Universidade de São Paulo (USP) com os documentos da Biblioteca Pública Municipal do Porto. Também no Porto, entrevistamos o professor e escritor Arnaldo Saraiva acerca da sua relação pessoal com Guimarães Rosa e da entrevista que realizou com o mineiro, publicada no Diário de Notícias (1966).4 Aliado a esses procedimentos, realizamos extensa pesquisa bibliográfica a partir das informações coletadas na leitura de cartas e entrevistas de Guimarães Rosa relacionadas ao tema.

\section{A genealogia dos Guimarães}

Após quatro anos de pesquisa em jornais do século XIX e início do XX, sobretudo em O Reflexo, A Verdade (Sete Lagoas), Folha do Cedro e Gazeta de Paraopebas (Paraopebas), e o Minas Geraes (Belo Horizonte), Alcântara (2020) acredita ter localizado aquele que seria o trisavô de Guimarães Rosa, o português Francisco de Assis Guimarães, dono de grandes extensões de terras, gado e escravos. Alcântara informa pouco sobre Francisco de Assis Guimarães, apenas que foi assassinado em setembro de 1850 por um de seus cativos, conhecido como Celestino Creoulo. Não se sabe, contudo, o motivo da morte. Celestino foi preso e condenado à forca, executado em 21 de novembro de 1850, uma quinta-feira, às 8 horas da manhã, em Curvelo, pelo carrasco conhecido como Fortunado (ALCÂNTARA, 2020, p. 19). Uma carta encontrada na Fazenda das Lajes, no distrito de Inhaúma, e publicada 57 anos depois, em 12 de maio de 1907, no jornal O Reflexo, de Sete Lagoas, traz o subtítulo: "Carta de um escravo em vésperas de ser enforcado", e teria sido ditada por Celestino Creoulo uma semana antes de ser enforcado. Na carta, ele pede perdão aos descendentes de Francisco Guimarães pelo ato, diz que tirou a vida de seu "bom senhor", "sem motivo nenhum, só por minha maldade".

Segundo o tio de Rosa, Vicente Guimarães (2006), o português Francisco de Assis Guimarães, deixou um único filho, que recebeu o mesmo nome do pai: Francisco de Assis Guimarães, ${ }^{5}$ nascido em 1844. Esse segundo Francisco de Assis Guimarães, ficaria conhecido como "Nhô

\footnotetext{
3 Heinrich Heine (1797-1856) foi um poeta, escritor e jornalista judeu-alemão. Considerado o último representante do movimento Romântico alemão e um dos responsáveis por sua superação. Estreou com o livro Poemas em 1822, no ano seguinte publicou Tragédias com o qual obteve amplo reconhecimento e cujos poemas foram musicados por diversos compositores como Schubert e Schumann Em 1827, a coletânea Livro das Canções granjeou-lhe grande reconhecimento em várias partes do mundo. Sua obra foi marcada também por aspectos políticos, a partir de sua amizade com Karl Marx. O seu lirismo melancólico ganhou, aos poucos, marcas acentuadas de ironia, em especial na última fase de sua vida.

4 ROSA, João Guimarães. João Guimarães Rosa - entrevistado por Arnaldo Saraiva. [Entrevista cedida a] Arnaldo Saraiva. Diário de Noticias, Porto, 24 set. 1966. Disponivel em: http://www.elfikurten.com.br/2011/01/grandes-entrevistas-guimaraes-rosa.html. Acesso em: 26 fev. 2020.

5 As pesquisas de Antônio Fernando de Alcântara, no entanto, nos jornais da região, sugerem a possibilidade de o português ter tido outros dois filhos: José Antônio de Assis Guimarães e Maria Francisca de Assis Guimarães.
} 
Chico" e herdaria as fazendas do pai morto, uma delas, a maior, chamada Três Barras. Como diria Guimarães Rosa sobre ela, era um "fazendão imenso, vetusto, antiga sede de sesmaria, hoje dividida em umas 30 fazendas". Em pesquisa que realizamos em igrejas e cartórios nas cidades de Guimarães e Braga, não encontramos nenhum registro referente a Francisco de Assis Guimarães, o que não inviabiliza a pesquisa de Alcântara.

Como se sabe, a cidade de Guimarães é cognominada o Berço de Portugal. A origem do nome é germânica Weihs Mar que resultaria primeiro em Weimar, depois Vimaranes e, finalmente, Guimarães. O significado original da palavra seria cavaleiro ou cavalo de combate, por isso Guimarães Rosa autodenominou-se o "Cavaleiro da Rosa do Burgo do Coração" (FERREIRA, 2017, p. 155), em referência à Cordisburgo, a sua cidade natal. Em Genealogia dos Guimarães (1974), Rui Moreira de Sá e Guerra conta que a origem dos Guimarães remonta de uma variada progenitura que descende de Dom Martinho de Castro dos Guimarães. Ele teria sido o primeiro a adotar para si o sobrenome. Dom Martinho nasceu em 11 de novembro de 1426, era escudeiro e tabelião-geral de El-Rei e arcebispo de Braga. Seu pai chamava-se Fernando da Guerra, que também foi arcebispo de Braga, e sua mãe chamava Joana da Cunha. Dom Martinho se casou com Leonor Fernandes Chamissa, senhora dos Chãos, e foi pai de Isabel Martins dos Guimarães, Pedro dos Guimarães, Lourenço de Castro dos Guimarães e Fernando dos Guimarães.

Portanto, Martinho de Castro Guimarães (1426 d.) foi o primeiro que comprovadamente assumiu para si o apelido "Guimarães", e o que recebeu maior atenção no estudo de Rui Moreira de Sá e Guerra (1974). Dom Martinho de Castro Guimarães era filho do arcebispo de Braga, Fernando da Guerra (1390-1447), que era por sua vez filho de Pedro João da Guerra (1366-1406), filho de João d'Eça Castro (1349-1397), Duque de Valencia dos Campos, que era filho de Pedro I (1320-1367), rei de Portugal com Inês de Castro (1320-1355). Pedro I foi o décimo rei de Portugal, tendo governado entre 28 de maio de 1357 e 18 de janeiro de 1367. O amor à terra natal faria Dom Martinho decidir misturar seu sobrenome à história da formação do território norte de Portugal. Ao longo do tempo, a familia passaria a ter diversos brasões (Imagem 1 e Imagem 2). De origem germânica, Weimar, Wigmar ou "cavalo (marah) de combate (wig)", o Vimara era a expressão da pessoa nascida em Wimaranis (vila, cidade ou quinta de Vimara). Em Guimarães, tinham ocorrido em 1128 os principais eventos políticos e militares que repercutiram com o nascimento de Portugal.

Imagem 1 - Brasão Família Guimarães

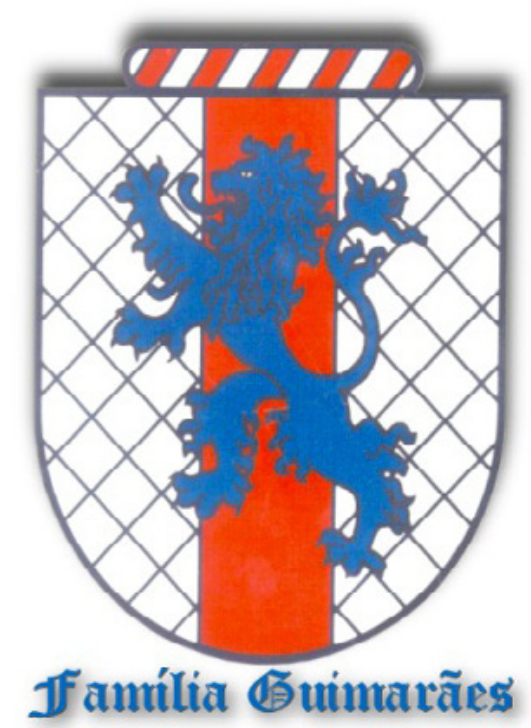

Fonte: Site Origem do Sobrenome. ${ }^{6}$

De acordo com Sá e Guerra (1974) e com levantamentos que realizamos em cartórios é provável que o primeiro "Guimarães" a colocar os pés em Minas Gerais tenha sido Jerônimo da Costa Guimarães, natural da freguesia de São Torquato, próximo à vila de Guimarães, no arcebispado de Braga, que teria migrado para o Brasil em 1733, e, a $1^{\circ}$ de novembro do mesmo ano, casou na igreja matriz da Freguesia de Carijós (atual Conselheiro Lafaiete), com Damiana Roza de São José, com quem teve oito filhos: Maria da Costa, Manoel, José, Amaro, Joaquim, João, Jerônima e Páschoa. Como era o costume da época, é provável também que muitos dos descendentes

6 Disponivel em: https://www.origemdosobrenome.com.br/familia-guimaraes. Acesso em: 15 mar. 2021. 
da familia "Costa Guimarães" tenham se casado entre si, alimentando a expressão popular que diz que "todo mineiro é primo".

Imagem 2 - Brasão da Família Guimarães em entalhado em madeira

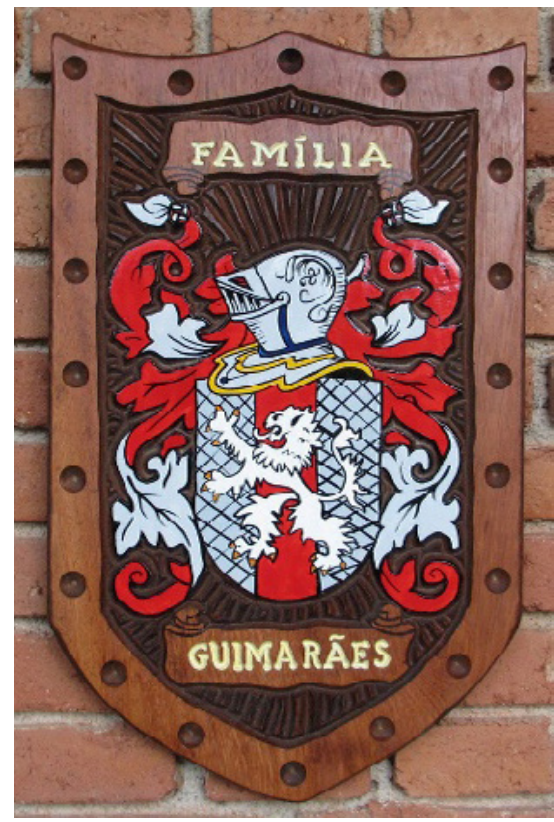

Fonte: Pinterest de Andy Lipsmeyer?

Em nossas pesquisas não encontramos a relação direta entre os "Costa Guimarães" e aquele que seria o trisavô de Guimarães Rosa, Francisco de Assis Guimarães. O que fica claro, contudo, na Genealogia dos Guimarães, de Sá e Guerra, é o grande número de ramificações que a família assumiu logo a partir de Dom Martinho de Castro Guimarães, sendo a familia "Costa Guimarães", oriunda da freguesia de São Torquato, apenas um desses ramos. Convém agora entender outras ligações de Guimarães Rosa com Portugal, em especial com seus intelectuais.

\section{Jaime Cortesão, Aquilino Ribeiro e Arnaldo Saraiva}

Um dos primeiros professores do recém fundado Instituto Rio Branco, inaugurado em 1945. na ocasião em que Rosa era chefe de gabinete do ministro das Relações Exteriores, João Neves da Fontoura (1887-1963), foi Jaime Cortesão (18841960), contratado por ser especialista na história da formação territorial brasileira e que tinha sido diretor da Biblioteca Nacional de Lisboa. Em 1922, Cortesão foi o responsável por trazer de Portugal ao Brasil a carta de Pero Vaz de Caminha, por ocasião da organização da Exposição do Quarto Centenário da Cidade de São Paulo (RIBEIRO, 2018, p. 8, 10).

Jaime Zuzarte Cortesão era médico, político, escritor e historiador e vivia exilado no Brasil desde 1940, devido à perseguição da ditadura de Antônio de Oliveira Salazar (1889-1970), que durou de 1932 a 1968. Quando saiu de Portugal, levou toda a familia para a Espanha, depois França, Bélgica e Inglaterra. Por fim, se fixou no Brasil. Era casado com Carolina Cortesão e tinha duas filhas, a primeira, Maria da Saudade Cortesão (1914-2010), tornou-se poeta e tradutora e viria a se casar com o poeta Murilo Mendes (1901-1975); a segunda, Maria Judith Zuzarte Cortesão (1915-2007), nascida no Porto, casou-se com o educador, historiador e filósofo Agostinho da Silva (1906-1994).

Cortesão era defensor da ideia de universidades populares e acentuava a importância dos intelectuais se voltarem para os saberes da tradição. Ele mesmo coletara os cantares populares em Portugal; defendia o uso de novas metodologias como a união do teatro com a educação e destacava a relevância imaginária e política das crianças, anunciada na "festa do divino espírito santo". Assim que retornou a Portugal, Cortesão foi indicado para concorrer à Presidência da República contra o Estado Novo. Nessa época, já era considerado um dos fundadores da chamada "Renascença portuguesa", embora perfilhado ao saudosismo de Pascoes: "Cortesão define-se como 'poeta da ação' e procura dinamizar no movimento projetos pedagógicos, numa ação idealista, voluntarista, altruísta e educativa, fundando as Universidades Populares e a revista $A$ Vida Portuguesa" (TRAVESSA, 2004).

Liderado pelo filósofo Teixeira de Pascoes $(1877-1952)^{8}$ e, depois, por Leonardo Coimbra 
(1883-1936), ${ }^{9}$ o chamado movimento cultural "Renascença portuguesa" pode ser sintetizado como: "um nacionalismo lírico espiritualista, neorromântico" (REAL, 2011). ${ }^{10} \mathrm{O}$ grupo invocava e retratava Portugal histórico, tradicional, interpretando que "o futuro de Portugal reside no seu passado" (REAL, 2011). Influentes, fundaram a revista Águia, para a qual colaborava Fernando Pessoa. Cortesão também fundou diversas revistas literárias e esteve próximo a António Sousa Pinto (1901-1987), dono da Livros do Brasil S.A., que viria a ser o editor de Guimarães Rosa em Portugal.

Em 1945, no recém fundado Instituto Rio Branco (IRB), Guimarães Rosa assistiu aos cursos de Cortesão sobre a análise de formação territorial do Brasil, em que ele expunha sobre o Tratado de Tordesilhas, o "descobrimento" e os estudos da cartografia. Naquele mesmo ano, Rosa seria eleito membro da Sociedade de Geografia do Rio de Janeiro, presidida pelo também diplomata José Carlos Macedo Soares, primeiro presidente e um dos fundadores do Instituto Brasileiro de Geografia e Estatística (IBGE). Da relação entre Guimarães Rosa e Cortesão, há inclusive um relato, segundo o qual, Cortesão teria, certa feita, visitado Rosa no Itamaraty com a finalidade de parabenizá-lo pelo estilo utilizado na crônica "História das Fadas", pois lembrava a fala e a escrita da época dos descobrimentos (VIANNA, 2019, p. 46).

Maria Celeste Natário (2010, 2011) observa que o cerne da filosofia portuguesa está na interseção entre poesia e pensamento, ambas unidas a uma "metafísica da experiência" centrada no silêncio, escuta, saudade, mistério e palavra. Dentre os poucos estudos entrelaçando Guimarães Rosa e Portugal, o de Susana Kampff Lages (2006) segue a mesma direção ao indicar que o escritor mineiro fazia uma "apropriação obliqua do mito da saudade, trazendo-o para dentro de sua própria definição de uma identidade brasileira, como algo de fundamentalmente ambivalente" (2006, p. 489). O tema da saudade é geralmente associado à "Renascença
Portuguesa" e ao filósofo Teixeira de Pascoes.

Lajes vê a influência literária de Portugal atuar sobre Rosa, sobretudo no domínio da língua e da literatura. Neste sentido, entendemos que é da figura de Aquilino Ribeiro que o mineiro se aproxima de modo particular. Tal aproximação já tinha sido destacada por Óscar Lopes (1964) e por Arnaldo Saraiva (1966). O escritor Aquilino Ribeiro era o quarto filho do padre Joaquim Francisco Ribeiro e da camponesa Mariana do Rosário Gomes, foi enviado para o seminário ainda menino, pois sua mãe queria que se tornasse sacerdote ${ }^{11}$ como o pai, mas não deu certo. Aquilino foi expulso do seminário em 1904, tornou-se maçom da Loja Montanha do Grande Oriente Lusitano, em Lisboa e, em 1907, foi preso acusado de anarquia, devido a uma explosão no seu quarto na Rua do Carrião, a 28 de novembro, em Lisboa.

No ano seguinte, em 1908, fugiu da prisão e do país, indo morar em Paris, estudou na Faculdade de Letras da Sorbonne, retornou a Portugal e foi trabalhar, em 1919, na Biblioteca Nacional de Portugal, onde conheceu Jaime Cortesão e Raul Proença. ${ }^{12}$ Naquele ano, publicou o livro Terras do Demo e, em 1930, O Homem que Matou o Diabo. Os temas relacionados ao diabo, a coleta das histórias e dos falares populares e o interesse pelo português medieval catalisavam seu interesse e o aproxima do mineiro. A linguagem de Ribeiro caracterizava-se pela excepcional riqueza lexicológica e pelo uso de construções frásicas de raiz popular, cheias de regionalismos.

Conheci Aquilino, mas acidentalmente. Eu entrei numa livraria, não sei qual, do Chiado (presumo que a Bertrand) e, quando pedi alguns livros dele, o empregado perguntou-me se eu queria conhecê-lo, pois estava ali mesmo. Respondi que sim, e desse modo obtive dois ou três autógrafos de Aquilino, com quem conversei alguns instantes. Voltei a estar com ele, mais tarde, num jantar que the foi oferecido enquanto de sua vinda ao Brasil. Mas ele, naturalmente, não se recordava de mim (porque eu não me apresentara como escritor), e eu também não lhe falei do assunto (ROSA, [1966]).

\footnotetext{
9 Leonardo José Coimbra foi um filósofo, professor e político português. Enquanto ministro da Instrução Pública de um dos governos de Primeira República Portuguesa, lançou as Universidades Populares e a Faculdade de Letras do Porto.

10 Também faziam parte do grupo António Correia de Oliveira, Augusto Casimiro e Mário Beirão.

11 O mesmo ocorreu a JGR que foi enviado aos 9 anos para o convento Santo Antônio, dos franciscanos, em São João Del Rei.

12 Raul Sangreman Proença (1884-1941), mais conhecido por Raul Proença, foi um escritor, jornalista, bibliotecário e filósofo português membro do grupo que fundou a revista Seara Nova e do chamado Grupo da Biblioteca (1919-1926), que se formou no tempo que Jaime Cortesão foi diretor da Biblioteca Nacional de Lisboa (1919-1926).
} 
Rosa contou o episódio vinte anos depois do ocorrido numa entrevista a Arnaldo Saraiva. Na época com 26 anos, Saraiva vivia no Rio de Janeiro, onde fazia pesquisas para defender uma tese de licenciatura em Letras na Universidade do Porto sobre Carlos Drummond de Andrade. Saraiva tinha se licenciado em Filologia Românica pela Faculdade de Letras da Universidade de Lisboa e assumiria a cadeira de Estudos Brasileiros e Africanos na Universidade do Porto. Ele viria também a estudar em Paris sob orientação de Roland Barthes, A. J. Greimas e Gérard Genette.

Quem apresentou Arnaldo Saraiva a Guimarães Rosa foi Carlos Drummond em uma recepção festiva na Livraria José Olympio. Drummond também apresentou Saraiva a Vinícius de Moraes e Manuel Bandeira. Segundo contou em depoimento a essa pesquisa, Rosa logo se mostrou simpático, quis conversar em um canto do salão. Saraiva notou que Rosa queria saber de Portugal: "Era muito interessado no que eu fazia" (SARAIVA, 2019). Perguntou notícias do editor Sousa Pinto, do crítico Óscar Lopes e da situação do país. A conversa prosseguiu durante duas horas. Antes de partir, Saraiva disse ao mineiro: "Olha, eu gostava de prolongar esta conversa para uma publicação" (SARAIVA, 2019). Rosa concordou e ponderou: "Eu não dou entrevistas" (ROSA, 2019, informação verbal), mas aceitou uma conversa, no Itamaraty, no dia seguinte.

No dia seguinte, lá estava Arnaldo Saraiva no Ministério. Na conversa com Rosa, ele perguntou da influência que o poeta recebera de Aquilino Ribeiro. O mineiro então disse:

Eu gosto de Aquilino, sobretudo da Aventura maravilhosa, mas não creio que dele tenha recebido alguma influência, a não ser na medida em que sou influenciado por tudo o que leio. A verdade é que antes de 1941 só conhecia de Aquilino um ou dois trechos, como infelizmente ainda hoje sucede em relação à quase totalidade dos escritores portugueses vivos. E, como sabe, Sagarana, foi escrito em 1937 (ROSA, [1966])

Ao falar que tirou a palavra "amouco" de Aquilino Ribeiro e que a utilizou no Grande sertão: Veredas
(1956), Rosa disse ainda sobre a escritura de seu único romance, algo "que nunca disse a ninguém":

E vou dizer-lhe uma coisa que nunca disse a ninguém: o que mais me influenciou, talvez, o que me deu coragem para escrever foi a História Trágico-Maritima. Já vê, por aqui, que as minhas "raizes" estão em Portugal e que. ao contrário do que possa parecer, não será grande a distância "linguística" que me separa dos portugueses (ROSA [1966]).

\section{A História Trágico-Marítima, "Correio Diplomático", Eça e a culinária}

Em 1735, Bernardo Gomes de Brito coligiu dezenas de relatos de naufrágios e os publicou no que viria a ser uma coleção "História Trágico-Maritima". Apesar da fama, a coletânea teve poucas edições, a segunda delas ocorreria apenas no fim do século XIX. A primeira reedição integral só foi publicada em 1942, dividida em seis volumes, preparados por Damião Peres. Em 1956 e 1957, surgiu uma edição em três tomos, organizada por António Sérgio, a quem coube notas e glossário. A primeira edição brasileira saiu em 1998 com introdução e notas de Alexei Bueno. O livro é uma coleção de relatos trágicos de naufrágios ocorridos com navegadores portugueses a partir 1536.

Kioko Koiso (2004) publicou um longo e detalhado estudo em dois volumes chamado Mar, medo e morte - Aspectos psicológicos dos náufragos na História Trágico-Maritima, nos testemunhos inéditos e noutras fontes. Koiso reuniu o maior número de pesquisas e abordagens sobre o tema publicados até 2004. Segundo ela, a História Trágico-Maritima é sobretudo um conjunto de relatos sobre o medo e a coragem. A riqueza de sua pesquisa está em tentar reconstruir as condições psicológicas que levaram Gomes de Brito à redação desta coleção de tragédias. Koiso (2004, p. 19) diz que Gomes de Brito sentia imensa admiração pelos navegadores que morreram naquelas condições. Em sua abordagem interdisciplinar, ${ }^{13}$ entende o fenômeno da "travessia" marítima como

13 Kioko Koiso encontrou várias fontes não publicadas sobre o tema, de modo que em sua compilação decidiu trazer essas contribuições. No primeiro volume, examina as questões filológicas e editoriais, os relatórios dos naufrágios e suas diferentes edições. No segundo volume, inclui esses relatórios inéditos, informando que os encontrou nas bibliotecas e arquivos portugueses. A transcrição de cinco desses manuscritos ocupa parte substancial do $2 .^{\circ}$ volume. 
o enfrentamento da própria adversidade. A morte e o medo do desaparecimento levaram muitos homens, segundo ela, a uma atitude mental semelhante à dos "samurais" ou "kamikazes" na Segunda Guerra: uma vida vivida no limite, regida sob a honra e o destemor radical. Uma coragem movida por algo suprafísico.

Sabemos que o tema das longas travessias, o medo, a coragem, a honra e a morte são questões presentes e conhecidas em Grande sertão: veredas. Podemos entender na frase de Rosa para Saraiva acerca do livro, ao dizer: "o que mais me influenciou, talvez, o que me deu coragem para escrever foi a História Trágico-Maritima" (ROSA, [1966]), que o tema da tragédia e da necessidade metafísica da coragem na travessia influenciaria o surgimento de Grande sertão: veredas. Sabemos que o tema da "coragem" em Rosa era um valor substancial. Nesse sentido, a aproximação entre os dois livros (ou duas tragédias) revelaria uma inesperada associação entre o sertão e o mar.

A visualização da "travessia" do difícil como experiência decisiva acerca do medo e da coragem, pode estar baseada em uma vivência concreta do próprio Guimarães Rosa. Em um texto inédito datado de 1952, sob o título "Correio diplomático", guardado no Acervo JGR, no Instituto de Estudos Brasileiros (IEB/USP), o mineiro resume o que foi atravessar a Europa entre maio e junho de 1941, em plena Segunda Guerra Mundial. Na época, ele servia como cônsul-adjunto em Hamburgo. Ao receber a missão de levar documentos e informações memorizadas até Lisboa, como correio diplomático, ele registrou a "aventura" de cruzar a Europa naqueles tempos:

Tempo de guerra, tudo vira aventura. Conto o que foi. Prévio, em Berlim, na embaixada, passei pelo preparo: o enfronho na massa política de assunto; mas, principalmente, acolhi entre outros dois conselhos: não desvigiar, nem minutos, de que Lisboa enxameava de agentes secretos, de ambos os campos, e, nos primeiros dias, não comer demais, por via de indigestão, tanto nossos estômagos se reduziam, desacostumados de fartura. Ver-ouvir, calar, frugalizar - um programa. Quando parti, quando entrei no avião, em Tempelhof, e os jornais da manhã davam o fim do 'Bismarck', nem pude me avolumar na noticia. Os deveres me exigiam. Além de ter que decorar algumas mensagens ultrassigilosas, quem me governava era uma valise, a dos papéis confidenciais, que devia jazer permanentemente debaixo de mão e de olho. Nada como a prática dos ingleses, 'correios do Rei', e de outros - resmunguei, suspirei - que viajam com a valise ou pasta afivelada ao pulso. Valesse-me, inda vem, o laisser-passer, em cinco idiomas, de que me haviam munido (ROSA, 1952).

Em 1941, depois de seguir de Hamburgo até Berlim, onde se encontrou com Freitas Valle para definir as estratégias da viagem, ficando ali três dias em preparação, Rosa tomou o avião até Stuttgart, depois outro até Lyon, onde comprou uma passagem para Marselha e outra para Barcelona. Em Barcelona, pegou outro voo até Madrid e, em seguida, outro para Lisboa, sem largar a valise. Na capital portuguesa, foi direto para a representação brasileira e entregou os documentos ao embaixador Araújo Jorge e seu primeiro secretário, Mendes Gonçalves. Após repassar as informações memorizadas, Rosa contou que caiu exausto na cama e dormiu o suficiente para poder se recompor e, no dia seguinte, ler jornais e bisbilhotar conversas nos cafés e restaurantes frequentados pela diplomacia internacional. Devia, sobretudo, atentar para a situação de Portugal no conflito. No dia seguinte, 7 de junho, começou a fazer o caminho de volta. Pegou um avião de Lisboa a Madrid, onde deveria ficar dois dias, com o mesmo propósito de colher informações, observar a cena, ler jornais, frequentar cafés e de novo, checar a situação de Espanha no conflito. Em Madrid, além de visitar o Museu do Prado, o Mosteiro e Sítio do Escorial, informou-se da relação naquele momento entre Espanha e Portugal. A 9 de junho, tomou o voo em Madrid que o levou até Berlim e dali seguiu de trem até Hamburgo. No total, foram dezoito dias de travessia.

$\mathrm{Na}$ entrevista concedida a Arnaldo Saraiva em 1966, Rosa contou outras relações que mantinha com Portugal:

Ainda continuo a gostar de Camilo, mas quem releio permanentemente é Eça de Queiroz (quando tenho uma gripe, faz mesmo parte da convalescença ler Os Maias; este ano já reli quase todo O Crime do Padre Amaro e parte da Ilustre Casa de Ramires). Camilo, leio-o como quem vai visitar o avô; Eça, leio-o como quem vai visitar a amante. Quando fui a Portugal pela primeira vez, eu só queria comidas ecianas (que 
gostosura, aquele jantar da Quinta de Tormes). Aliás deixe-me que the diga que me torno muito materialista quando penso em Portugal; penso logo nos bons vinhos, nas excelentes comidas que há por lá. E talvez seja também por isso que se há um país a que eu gostaria de voltar é Portugal [...] (ROSA, [1966]).

Antes daquela vez, em 1941, em que foi Correio Diplomático, esteve em Lisboa em 1938, vindo a bordo do vapor General Artigas a caminho de Hamburgo, seu primeiro posto no exterior. Rosa passou pelas ilhas de Cabo Verde e Canárias, dois dias depois, chegou à Itha da Madeira. No dia seguinte, chegou a Lisboa. O vapor seguiu costeando o litoral de Portugal, não se afastando além de 70 milhas, era a norma da época, por precaução das minas submarinas.

A terceira vez que Rosa esteve em Portugal foi em 1942. Ele ficou um mês na cidade, após o confinamento de três meses em Baden-Baden, devido à tomada de posição do Brasil a favor dos Aliados na Segunda Guerra Mundial. Guimarães Rosa e mais 36 diplomatas com suas esposas e filhos foram trocados por diplomatas alemães vindos do Brasil. Chegando a Lisboa, Rosa ficou hospedado com Aracy Moebius, sua futura esposa, em uma pensão da Rua do Ouro, 65.

Como se viu, mais do que um olhar literário, Rosa costumava lançar um viso culinário sobre Portugal a partir da obra de Eça de Queiroz. Não se tratava de um detalhe menor, tendo em vista a pesquisa que Maria de Lourdes Modesto e Beatriz Berrini realizaram na obra de Queiroz, em especial em Os Maias (1888), Primeiro Basilio (1878) As Cidades e as serras (1901) e O Mandarim (1880). Na obra Comer e Beber com Eça de Queiroz (1995), Modesto e Berrini compilaram mais de 50 receitas, entre elas: "Galinha afogada em arroz", "Arroz de favas", "Folhados de Cocó", "Sopa seca de pão com presunto e legumes", "Jambon aux épinards", "Coelho guisado à moda da Porcalhota", "Arroz de forna", "Bacalhau com pimentos e grão-de-bico", entre outros. Há ainda pratos com peixe, carne, aves, queijos, ovos, e sopas, vinhos, broas, biscoitos, bolos e sobremesas.

Ao justificar em uma carta a António Souza Pinto, datada de 21 de março de 1963, "não ter sido possivel dar uma chegada" a Lisboa, quando da sua viagem à Europa, Rosa disse: "Creia, também lamentei muito não ter podido passar uns dias em Lisboa. Sempre gostei dos portugueses" (ROSA, 1963). Em seguida, confessou:

Gente de muito coração e solidez de caráter. Depois...tudo. O ar, o céu, os fados, os mosteiros históricos, os vinhos, a comida - ah, um arroz-de-pato minhoto, as amêijoas, os ovos com chouriços, os berbigões, as lulas... a marmelada de Odivellas, os doces de ovos... e as frutas: as nêsperas e uvas, os pêssegos. Comer, na primeira refeição da manhã, pão untado com o incomparável mel das abelhas do Algarve. nutridas com o pólen e o néctar das amendoeiras em flor... Mas, devo conter-me, aqui, que a gula se me desenfreia (ROSA, 1963).

\section{António Sousa Pinto e Óscar Lopes}

A relação de Rosa com o editor António Augusto de Sousa Pinto (1901-1987)14 se prolonga entre 1951 e 1967. Sousa Pinto era sócio e editor de Jaime Cortesão e foi responsável pela publicação de Rosa na sua editora, a Livros do Brasil Ltda (VIANNA, 2019, p. 102). Na época da primeira publicação em Portugal, quem cuidou diretamente das publicações foi o jovem diplomata Alberto da Costa e Silva. Segundo Covizzi e Verlangieri (1996), os livros ali publicados (por ordem cronológica) foram: em 1951: Sagarana (prefácio e glossário: Alberto da Costa e Silva); em 1961, Miguilim e Manuelzão, que reúne as novelas "Campo Geral" e "Uma estória de Amor"; em 1964, A Aventura nos Campos Gerais, com "A estória de Lélio e Lina", "Recado do Morro" e "Cara de Bronze"; em 1966, Noites do Sertão, com "Dão-Lalaão" e "Buriti". Em 1957, em colaboração com outros autores, ${ }^{15}$ saiu Os sete pecados capitais, com o conto "Os Chapéus Transeuntes" (capítulo I, "A soberba", também pela Livros do Brasil). O conto posteriormente

\footnotetext{
14 Ele também criou várias editoras e livrarias. Caracterizou seu trabalho pela divulgação da herança cultural portuguesa no Brasil por meio da editora Livros de Portugal, da qual foi diretor Jaime Cortesão. Da mesma forma, por meio de sua editora Livros do Brasil, divulgou autores brasileiros em Portugal, dentre os quais, João Guimarães Rosa (Cf. MELO, 2018, p. 1).

15 Outros narradores presentes na obra: Otto Lara Resende, Carlos Heitor Cony, Mário Donato, Guilherme Figueiredo, José Condé e Lygia Fagundes Telles. Cf.: ROSA, João Guimarães et al. Os sete pecados capitais. Rio de Janeiro: Civilização Brasileira, 1964.268 p.
} 
foi incluido em Estas Estórias (Rio de Janeiro, J. Olympio, 1969). Após esse período, nada mais foi publicado até 2019, quando saiu pela Cia das Letras, Grande sertão: veredas.

Desde 1951, nas cartas entre Rosa e Souza Pinto, o editor português fazia questão de falar de Óscar Lopes para o mineiro, a essa altura já um eminente professor e crítico literário. Guimarães Rosa e Óscar Luso de Freitas Lopes nunca se conheceram pessoalmente, no entanto, poucas pessoas lutaram tanto pelo reconhecimento internacional do brasileiro como ele. Óscar Lopes se graduou em Filologia Clássica, na Universidade de Lisboa, em História, em Coimbra e em Música, no Conservatório do Porto. Foi professor de literatura e de linguística durante toda a vida, primeiro em liceus, entre 1941 e 1974, depois, a partir de 1975 . como professor na Faculdade de Letras da Universidade do Porto, onde acabou se aposentando.

Além de professor, foi célebre crítico literário, com colaborações em jornais e revistas (Seara Nova, Vértice, Mundo Literário etc.). Entre outros Livros, ${ }^{16}$ assinava o História da Literatura Portuguesa (1955), em colaboração com António José Saraiva; uma biografia de Jaime Cortesão (Arcádia, 1962) e outra de Antero de Quental (Caminho, 1983). Criador da Universidade Popular do Porto, em 1979, pertencia ao Movimento da Unidade Nacional Antifascista e à Comissão Nacional de socorro aos presos políticos, o que lhe angariou a antipatia do regime Salazarista. Militante do Parti- do Comunista Português desde 1945, Lopes faria parte de seu Comitê Central entre 1976 e 1996.

Sousa Pinto enviou a Rosa em anexo à carta datada de 3 de julho de 1964 a intervenção de Óscar Lopes na reunião do júri do Prêmio Internacional de Editores (conhecido como Prêmio Fomentor) (PINTO, 1964). Lopes tinha dado uma entrevista no programa "Paisagem Intelectual", da Rádio Clube, em que leu um texto apoiando a candidatura de Grande sertão: veredas ao Prêmio Fomentor. Era justo o texto que Pinto enviava ao mineiro anexado à carta de 3 de julho.

A $3^{a}$ reunião do júri para atribuição do Prêmio Fomentor tinha ocorrido em Salzburgo naquele ano com a presença de 50 críticos $^{17}$ de 17 países, que se puseram a discutir 72 obras, previamente selecionadas. Óscar Lopes e Mário Dionísio eram os representantes da língua portuguesa. Dionísio apresentou o Barranco dos Cegos (1961), de Alves Redol, e As Palavras Poupadas (1961), de Maria Judite de Carvalho, enquanto Lopes indicou Grande sertão: Veredas, de Rosa, e Gabriela Cravo e Canela, de Jorge Amado. Sobre Grande sertão: Veredas, redigiu uma monografia ${ }^{18}$ e um texto menor que leu na rádio Clube. Na terceira pergunta do programa, o locutor indagou: "E quanto a João Guimarães Rosa?". Lopes respondeu o seguinte:

Ora aí está... Apesar das suas peculiaridades de estilo, que fazem com que seja tudo como uma espécie de Aquilino Ribeiro do Brasil. Não se pode dizer que Guimarães Rosa seja um desconhecido fora do domínio linguístico

16 Escreveu ainda Album de Familia: Ensaios sobre Autores Portugueses do Século XIX (1984); Os Sinais e os Sentidos: Literatura Portuguesa do Século XX (1986): Entre Fialho e Nemésio: Estudos de Literatura Portuguesa Contemporânea (1987); A Busca de Sentido: Questões de Literatura Portuguesa (1994); 5 Motivos de Meditação: Luís de Camões, Eça de Queirós, Raul Brandão, Aquilino Ribeiro, Fernando Pessoa (1999). 17 George Weidenfeld (diretor da Weidenfeld \& Nicolson, Londres. presidente do "Prix International de Littérature" e do "Prix Formentor" de 1964); Willem Bloemena (diretor do J. M. Eulenhoff, Amsterdam); Prince Azamat Guirey (Weidenfeld \& Nicolson, Londres); (membros do Reino Unido. Holanda e Canadá): Robert Baldick; Jacques den Haan; Friedrich Heer; Melvin Lasky: Mary McCarthy: Jonathan Miller: Jan Walravens; John Weightman; Barley Alison; Claude Gallimard (diretor da Gallimard, Paris); (membros da Frsnça): Dominique Aury; C G. Bjurström; Michel Butor; Roger Caillois; François Erval; Michel Mohrt; Jean Paulhan; Jorge Semprún; Dionys Mascolo; Monique Langue: Heinrich Ledig-Rowohlt (Director of Rowohlt Verlag. Paris); (membros da Alemanha): Beda Allemann; François Bondy; Hans Magnus Enzensberger; Adolf Frisé; Hans Meyer; Fritz Raddatz; Giulio Einaudi (director of Giulio Einaudi Editore, Turin); Giulio Bollati (Giulio Einaudi Editore, Turim); (membros da Itália): Gabriele Baldini; Italo Calvino; Cesare Cases; Gianfranco Contini; Carlo Levi; Alberto Moravia; Guido Piovene; Angelo Ripellino; Paolo Spriano ("Ufficio Stampa); Elio Vittorini; Guido Davico Bonino; Harald Grieg (diretor da Gyldendal, Oslo); Otto B Lindhardt (diretor da Gyldendalske Boghandel, Copenhagen); Erkki Reenpää (diretor da Kustannusosakeyhtiö Otava, Helsinki); Georg Svenson (Diretor da Albert Nonniers Förlag. Stockhlm); (Membros da Finlândia, Escandinávia, Dinamarca e Suécia): Gunnar Brandell; Lars Gustafsson; Uffe Harder; Kai Laitinen; Carlos Barral (diretor da Editorial Seix Barral, Barcelona); António José Guerra da Cruz Barreto (Diretor da Editora Arcadia, Lisboa); (Membros da Espanha, Portugal e América): José M. Castellet; Mário Dionísio; Oscar Lopes; Fernando Morán; Mario Vargas Llosa; Barney Rosset (diretor da Grove Press, New York); Milton Perlman (Grove Press, New York); (membros dos EUA): Kay Cicellis; Herbert Golg; Fred Jordan; Donald Keene; Kushwant Singht; Richard Seaver; Jaime Salinas. (secretário-geral do "Prix International de Littératures" e "Prix Formentor"); Elisabeth Hohenloche (secretária); Vera Dridso (secretária do secretário-geral). Naquele ano o prêmio acabou sendo atribuido a Les Fruits d'or, de Nathalie Sarraute.

18 Além da "Proposta de candidatura ao prêmio Internacional de Literatura 1964", Óscar Lopes escreveu ainda: "Cosmorama de Guimarães Rosa: uma sintese" (1962); "Sôroco sua mãe, sua filha" (1965) e "Tutameia" (1967), todos publicado em Ler e Depois: critica e interpretação literária (Porto: Inova, 1970). 
português. A Sagarana, e novelas extraídas do Corpo de Baile, como o Miguilim e Manuelzão, têm já tradução francesa, e graças a estes dois livros (que aliás o público português também conhece em edições de Livros do Brasil), a candidatura que eu propus teve o apoio caloroso da Delegação francesa, pela voz de Roger Caillois. Roger Caillois apontou Guimarães Rosa como um caso único na ficção sul-americana. No entanto, o romance proposto, Grande sertão: Veredas, tinha apenas uma tradução inglesa recente. Mesmo assim, o resultado obtido foi compensatório: ali mesmo, em Salzburgo, deu-se o primeiro passo para a tradução francesa imediata do livro. E ele figurou entre as obras escolhidas na primeira votação, que não era decisiva, mas era eliminatória. Uma honra que partilhou com mais de uma meia dúzia de livros, e que, concretamente, significa isto; tinha por si a unanimidade de uma das sete secções do júri, além de votos dispersos e pedidos entre as outras secções. Como o livro pode ser ainda proposto em 1965, visto ainda então não se terem completado dez anos de edição original, estou convencido de que, graças a João Guimarães Rosa, a ficção de língua portuguesa poderá, então, vir a ser distinguida com esse Prêmio (LOPES, 1964).

Em seguida, o apresentador quis saber se a literatura do brasileiro estava "ao nivel da melhor ficção mundial contemporânea". Lopes disse:

Tanto quando me é dado conhecer o melhor da ficção mundial contemporânea, através das candidaturas ao Prêmio, não tenho grandes dúvidas a esse respeito. As razões do que digo poderão ser desenvolvidamente conhecidas, lendo no último Seara Nova, o texto da minha comunicação em Salzburgo. Muito em resumo, limitar-me-ei a dizer aqui o seguinte: Guimarães Rosa tira do português falado no Brasil, e nomeadamente no Sertão, um partido poético comparável ao do melhor inglês de James Joyce, ao dos prosadores mais acertadamente audaciosos das linguas mais lidas. E, como ficcionista, consegue, no Grande sertão: Veredas realizar esta proeza: pôr em termos actuais e brasileiros, e de um modo que impressiona, que nos empenha pessoalmente, o tema do Fausto de Goethe, isto é, o tema do pacto com o Diabo. E não sabia que temos todos um pacto com o Diabo? - Pois leia, e verá... Além desse tema, actualiza também o grande tema da Oréstia de Ésquilo, vem a ser: o tema da legitimidade da vingança, incluindo qualquer forma de castigo ou repressão... A gente acaba de ler o romance, e parece que a nossa experiência se enriqueceu extraordinariamente, parece que a nossa responsabilidade pessoal se tornou mais aguda. Fica-nos na cabeça o principal estribilho do narrador, que é um antigo cangaceiro, um antigo chefe de bando no Sertão. Diz ele constantemente, e cada vez de modo mais persuasivo, ao longo da sua história: viver é perigoso. Diabolicamente perigoso! Além disso é um romance cheio de acção, de episódios intensamente dramáticos nas lutas entre bandos de jagunços, um romance em que de vez em quando nos achamos em pleno maravilhoso, mas um maravilhoso real, autênticos momentos de céu ou então de inferno na terra: uma suma do homem, de todas as facetas do homem, nas condições do grande sertão brasileiro, amplo como todo um continente. Sob este aspecto, o romance é, por assim dizer, a actualização da Divina Comédia, ou ainda da epopeia bárbara: de Cid, El Campeador ou da Chanson de Roland. E isto sem deixar de assimilar as mais modernas técnicas da narração, sem deixar de ser um romance de hoje: por exemplo, no flash back. isto é, na maneira de saltar para trás e para frente, no tempo, a fim de obter os melhores efeitos de ritmo narrativo e de alternância entre os seus temas, este romance não fica nada a dever ao chamado nouveau roman francês ou alemão. Devo, no entanto, advertir os que neste momento me ouvem e porventura se venham a interessar por Guimarães Rosa de uma coisa: as primeiras páginas do livro podem descorçoar quem não esteja acostumado ao estilo do autor, às suas ousadias estilísticas, aliás muito oralmente brasileiras, e especialmente sertanejas. Eu aconselharia que, seguindo a ordem de elaboração da sua já agora notabilissima obra, lessem primeiro Sagarana, e Miguilim e Manuelzão, ou ainda a última novela de Corpo de Baile, chamada "Buriti", que tanto entusiasmou a crítica francesa. Aliás tem sido esta a ordem, em geral, das suas edições fora do Brasil, como creio já ter sugerido ainda há pouco [...] (LOPES, 1964).

\section{Considerações finais}

A ligação de Rosa com Portugal nos revela muito mais um conjunto de ligações afetivas, intelectuais e editoriais do que propriamente um conhecimento real a partir da experiência vivida. Mesmo sem ter visitado nenhuma outra região do país além de Lisboa, ele construiu para si uma relação imaginária forte com a cultura e o povo. Essa relação passava muito mais pela literatura, gastronomia e trocas intelectuais do que por outras vias. Levando-se em conta que Rosa morou na Europa dois longos períodos, na Alemanha (entre 1938-42) e na França (entre 1948-51), sendo que no periodo francês visitou a Itália duas vezes (em 1949 e 50), verificamos a falta de interesse por viagens de imersão à Portugal.

Ainda assim, acreditamos na possibilidade de um maior aprofundamento na investigação das relações entre Guimarães Rosa e Portugal. Entre esses aprofundamentos podemos indicar: a recep- 
ção crítica na imprensa e no público das obras ali publicadas; a influência de Jaime Cortesão no seu interesse pela geografia e pelo tema do "divino" sob o recorte da criança e do "Espírito Santo" advindos do imaginário e da espiritualidade portuguesa medieval; o tema da culinária em sua correlação literária com Eça de Queiroz; as várias semelhanças e aproximações com Aquilino Ribeiro; o conjunto de cartas trocadas com o editor António de Souza Pinto; as formas de "presença" da História Trágico-Maritima (1735), de Bernardo Gomes de Brito, no romance Grande sertão: veredas, entre outras possibilidades. Do mesmo modo, entendemos que a aproximação entre Rosa e Óscar Lopes pode redundar em novas chaves interpretativas e críticas da obra do mineiro.

\section{Referências}

ALCANTARA, Antônio F. Paragens de Rosa - Uma trajetória singular. Belo Horizonte: Ed. do autor, 2020.

BERRINI, Beatriz; MODESTO, Maria de Lourdes. Comer e beber em Eça de Queiroz. Lisboa: Alêtheia Editores, 1995.

BRITO, Bernardo Gomes (compilação). História trágico-marítima. Introdução e notas de Alexei Bueno. Rio de Janeiro: Lacerda Editores: Contraponto, 1998.

COVIZZI, Lenira M.; VERLANGIERI, Iná V. R. Pequena Bibliografia de João Guimarães Rosa. Revista do Instituto de Estudos Brasileiros, n. 41, p. 213-232, 1996.

FERREIRA, Ermelinda M. A. Poetas heteronímicos e anagramáticos. Revista Via Atlântica, São Paulo, n. 32, p. 149-175, dez. 2017.

GUIMARÃES, Vicente. Joãozito - a infância de João Guimarães Rosa. São Paulo: Panda Books, 2006.

HARSS, Luis. Los Nuestros. Barcelona: Alfaguara, 2012.

HOLLERER, Walter. Séries de TV. Sender Freies Berlin. Berlim: 1962. (6 minutos e 46 segundos).

KOISO, Kioko. Mar, medo e morte: aspectos psicológicos dos náufragos na História Trágico-Maritima, nos testemunhos inéditos e noutras fontes. Carnaxide: Patrimonia; Cascais, 2004. 2 V.

LAGES, Susana Kampff. A Europa de Guimarães Rosa e de Eduardo Lourenço: Portugal, Europa e os não- lugares da saudade. In: CONGRESSO NACIONAL DO CINQUETENÁRIO DE GRANDE SERTÃO: VEREDAS \& CORPO DE BAILE, 1, 2006, Rio de Janeiro. Anais [...]. Rio de Janeiro: Faculdade de Letras, UFRJ, 2006.

LOPES, Óscar. Paisagem intelectual. Lisboa, 2 jul. 1964. Programa de rádio. Documento JGR-CE-01,41.

LOPES, Óscar. Ler e Depois: crítica e interpretação Literária. Porto: Inova, 1970.
MELO, Daniel. Semblanza de António de Sousa Pinto (1901-1987). Biblioteca Virtual Miguel de Cervantes Portal Editores y Editoriales Iberoamericanos (siglos XIX-XXI). Disponivel em: http://Www.cervantesvirtual. com/buscador/?q=Semblanza+de+Ant\%C3\% B3nio+de+Sousa+Pinto+. Acesso em: 18 fev. 2020.

NATÁRIO, Maria Celeste. Itinerário do pensamento filosófico português. Pref. António Braz Teixeira.1. ed. Sintra: Zéfiro, 2010

NATÁRIO, Maria Celeste. Entre a filosofia e a literatura.1. ed. Sintra: Zéfiro, 2011.

PINTO, António de Sousa. [Correspondência]. Destinatário: João Guimarães Rosa. Lisboa, 3 jul. 1964. Documento JGR-CE-01,40

RIBEIRO, David W. A. Uma exposição para o IV Centenário de São Paulo: um historiador português narra a "história bandeirante". An. mus. paul. [online], v. 26, e23, nov. 23, 2018. ISSN 0101-4714.

REAL, Miguel. O espiritualismo d'A Águia. Cultura Revista de História e Teoria das Ideias, Lisboa, v. 28, p. 237-255, 2011.

ROSA, João Guimarães. [Correspondência]. Destinatário: António de Sousa Pinto. Rio de Janeiro, 21 mar. 1963. Documento JGR-CE-01,30.

ROSA, João Guimarães. [Correspondência]. Destinatário: António de Sousa Pinto. Rio de Janeiro, 12 maio 1965. Documento JGR-CE-01,48.

ROSA, João Guimarães. Correio diplomático. Inédito. Rio de Janeiro. 1952. Documento JGR-EO-18,03-8

ROSA, João Guimarães. João Guimarães Rosa - entrevistado por Arnaldo Saraiva. [Entrevista cedida a] Arnaldo Saraiva. Diário de Notícias, Porto, 24 set. 1966. Disponivel em: http://www.elfikurten.com.br/2011/01/grandes-entrevistas-guimaraes-rosa.html. Acesso em: 26 fev. 2020.

SARAIVA, Arnaldo. Depoimento. Entrevistador: Gustavo de Castro. Entrevistado: Arnaldo Saraiva. Porto: Projeto Relação com Portugal no perfil biográfico João Guimarães Rosa, set. 2019. 1 fita. (60 min)

SÁ E GUERRA, Rui Moreira de. Genealogia dos Guimarães. Braga: Estudos Histórico e Genealógicos, 1974.

TRAVESSA, Elisa N. Pedagogia Cívica em Jaime Cortesão. Revista do Centro de História da Universidade de Lisboa, Lisboa, n. 8, $1^{\circ}$ sem. 2003. Disponivel em: http:// cvc.instituto-camoes.pt/seculo-XX/jaime-cortesao-dp1. html\#.W-SSmpNKiUk. Acesso em: 20 fev. 2020

VIANNA, Andrea R. J. o jornalismo em Guimarães Rosa: aproximações. 2019. 196 f. Dissertação (Mestrado em Comunicação) - Faculdade de Comunicação, Universidade de Brasília, Brasilia, 2019

\section{Agradecimentos}

Pesquisa financiada pelo Edital DPI/DPG-UnB 03/2020 (Processo SEl: 23106.056973/2020-72); pelo Edital DPG-UnB/FAP-DF (Processo SEl: 23106.015.149/2019-29) e pelo CNPq (Processo 
304229/2020-2), mediante Bolsa PQ. Agradecemos a colaboração de Clara Rowland e do Instituto de Estudos de Literatura e Tradição (IELT) da Universidade Nova de Lisboa (UNL).

\section{Gustavo de Castro}

Doutor em Ciências Sociais pela Pontificia Universidade Católica de São Paulo (PUC-SP), em São Paulo, SP, Brasil; professor do Programa de Pós-Graduação em Comunicação da Universidade de Brasília (UnB), em Brasilia, DF, Brasil.

\section{Paulo Alziro Schnor}

Mestre em Comunicação Social pela Universidade de Brasília (UnB), em Brasília, DF, Brasil; pesquisador do Grupo Siruiz de Comunicação e produção literária.

Endereço para correspondência

Gustavo de Castro

Universidade de Brasilia

Faculdade de Comunicação

Campus Darcy Ribeiro

ICC Norte, 70910-900

Brasilia, DF, Brasil 